\title{
Lifestyle Risk Factors in Noncommunicable Diseases- Major Hurdles in Attaining Sustainable Development Goals in India
}

\author{
Malavika Bhattacharya \\ Department of Biotechnology \\ Techno India University, West Bengal \\ Kolkata, India
}

\begin{abstract}
Sustainable developmental goals (SDGs) have been framed with the aim of achieving overall betterment of people belonging to all economic strata. In particular, SDG-3, the main health-related goal is aimed towards "ensuring healthy lives and promoting well-being for all in all ages". As part of this goal, the growing epidemic of non-communicable diseases (NCDs) has been allotted high priority. The current scenario of occurrence and prevalence of various NCDs (especially diabetes, obesity, cancers and cardiovascular diseases) in India is alarming and a cause of growing concern for the nation which is already dealing with an exponentially growing population, crumbling basic public healthcare facilities and poverty. Since majority of these NCDs occur because of various lifestyle related risk factors such as addiction (tobacco, alcohol), food habits (malnutrition, both subnutrition/ undernutrition and overnutrition) and physical inactivity, appropriate interventions addressing these aspects can help in decreasing the number of occurrences/premature deaths due to NCDs. This study reviewed and analyzed currently available information on these major contributing factors, their burdens on the society (with reference to NCDs, in particular) and the various inclusive growth measures that can contribute towards addressing this problem.
\end{abstract}

Keywords-Addiction; Lifestyle-related risk factors; Malnutrition; Non-communicable diseases; Sustainable Development Goals

\section{INTRODUCTION}

The vision of inclusive growth across the globe has paved way for formation of Sustainable Development Goals (SDGs) by the UN General Assembly (United Nations, 2015). These goals were formulated to replace the Millenium Development Goals (MDGs) in September 2015 (United Nations Millennium Project, 2015). With the deadline of the year 2030 and formation of an Inter-Agency and Expert Group on Sustainable Development Goal Indicators (IAEG-SDGs) for monitoring the progress of work (IAEG-SDGs, 2016), SDGs appear to be more realistic and achievable. Out of 17 of them, number three is primarily aimed towards improving health status of all. Since inclusive growth is the basis of the SDGs, out of its seven pillars, numbers one (Education and skills), two (Basic services and infrastructure) and seven (Fiscal transfers) are vital parameters which can give accurate information regarding progress of these goals, especially SDG-3 (The Inclusive Growth and Development Report, 2017).

Globally, there has been rapid increase in occurrence rate of various non-communicable diseases (such as diabetes, obesity, cancers, respiratory diseases and cardiovascular diseases) (Terzic and Waldman, 2011). This trend is not only detrimental with reference to human health, but also in context of economic growth and development of the nation. The situation is alarming in India as this country is faced with twin problems of exponential population growth and steep rise in number of people falling prey to NCDs. The major contributors in this shift towards NCDs are behavioral and lifestyle-related risk factors which can be associated with the environment and culture surrounding an individual (World Health Organisation, 2009; Ezzati and Riboli, 2013). Thus, mere efforts of the governments (central and state) and NGOs will not be sufficient, and awareness and efforts at individual level will be essential.

\section{MATERIALS AND METHODS}

Occurrence rates of non-communicable diseases have seen exponential growth in India in recent past. The trend is even more alarming for the future. In addition to the extremely high rate of population growth, various lifestyle-related risk factors are turning out to be major contributors towards these high occurrence rates. This study aimed towards understanding the current situation in this context with reference to India, in particular. With this aim, review and analysis was carried out on various publications, articles and reports available and related to this area of research. Increasing populations, inequal distribution of basic facilities (such as food, housing, sanitation, education and primary healthcare facilties), increasing poverty levels and unemployment, and various societal discriminations are pushing a significant proportion of the country's population towards NCDs.

\section{FINDINGS}

\section{A. Overview of Sustainable Development Goals (SDGs)}

As mentioned earlier, the SDGs replaced the Millenium Development Goals (MDGs) and 93 nations (including India) adopted them in the United Nations Summit held in September, 2015. These SDGs were brought into effect from $1^{\text {st }}$ January, 2016. A total of 17 SDGs and 169 targets have been chalked out keeping complete inclusive growth of all individuals in view (Achieving the Sustainable Development Goals in India, 2015). Out of these 17 goals, goal number 3 has special significance in context of the healthcare sector as its aim is to "Ensure healthy lives and promote well-being for 
all at all ages" (Achieving the Sustainable Development Goals in India, 2015).

\section{B. SDGs and healthcare sector}

Out of the various subclauses under SDG-3, the following are most important and relevant in context of the healthcare sector and NCDs, in particular (Achieving the Sustainable Development Goals in India, 2015):

- 3.4 By 2030, reduce by one third premature mortality from non-communicable diseases through prevention and treatment and promote mental health and well being

- 3.5 Strengthen the prevention and treatment of substance abuse, including narcotic drug abuse and harmful use of alcohol

- $\quad 3.9$ By 2030, substantially reduce the number of deaths and illnesses from hazardous chemicals and air, water and soil pollution and contamination

Moreover, the following subclauses have also designed to provide a direction for implementing these goals (Achieving the Sustainable Development Goals in India, 2015):

- 3.a Strengthen the implementation of the world health organization framework convention on tobacco control in all countries, as appropriate

- 3.b Support the research and development of vaccines and medicines for the communicable and noncommunicable diseases that primarily affect developing countries, provide access to affordable essential medicines and vaccines

- 3.c Substantially increase health financing and the recruitment, development, training and retention of the health workforce in developing countries, especially in least developed countries and small island developing states

- 3.d Strengthen the capacity of all countries, in particular developing countries, for early warning, risk reduction and management of national and global health risks

\section{Severity of non-communicable diseases (NCDs) in India}

Non-communicable diseases have shown significant increase in India. World Health Organization report has shown that, in this country, $53 \%$ of all deaths are caused by NCDs (World health organization, 2011). Out of all the commonly occurring NCDs, cardiovascular diseases account for maximum disease burden, followed by respiratory diseases, cancer and diabetes (Report of the working group on disease burden for 12th five year plan, 2011). Furthermore, it has been found that approximately 10 lakh new cases of cancer are reported every year and various forms of cancer account for the maximum number of NCD deaths in India diabetes (Report of the working group on disease burden for 12th five year plan, 2011). Diabetes, another major contributor, has been found to be responsible for over 1 lakh deaths in a year in this country. An estimate shows that currently over 40 million people are suffering from diabetes here, and these figures will go upto 69.9 million by the year 2025 diabetes (Report of the working group on disease burden for 12th five year plan, 2011). A recent study has reported that in the year 2016, around 62\% of the deaths in India occurred due to NCDs (ICMR, PHFI, and IHME, 2017).

\section{Economic burden of NCDs in India}

Since India is a growing economy and superpower in making, and because it has an exponentially growing population, health of its people is of utmost importance. An ailing population is not only an economic burden for a country, but also a loss of potential human resource. It is manifested in several forms including early retirement, loss of efficiency, mental agony reflected in depression and negative attitude, loss of confidence and failure to lead a normal life, not to mention the expenditures on treatment procedures. Estimates indicate that India is set to make losses of around $\$ 4.58$ trillion between years 2012 to 2030 on account of NCDs and mental health conditions, with the highest loss due to cardiovascular diseases ( $\$ 2.17$ trillion) (Economics of NonCommunicable Diseases in India, 2014). Another study has reported that in the year 2010, DALY (disability-adjusted life years) was higher for non-communicable diseases (233 million) in comparison to that for communicable diseases (222 million) (Institute for Health Metrics and Evaluation, 2013). However, there is hope as interventions and efforts towards prevention and early detection of the NCDs can reverse the situation, at least to some extent. Since lifestyle risk factors have been found to be significant contributors towards occurrence of NCDs, changing daily habits and derogatory routines at individual level can prove to be helpful. In fact, estimates have indicated that premature NCD-related deaths can be decreased by as much as $40-50 \%$ by efforts to curtail these risk factors at individual levels (Taylor, 2010).

\section{E. Lifestyle risk factors and NCDs}

Increasing evidences are showing that lifestyle or behavioral risk factors are contributing heavily towards pushing up incidence rates of NCDs. Predictions indicate that various types of lifestyle risk factors such as addiction for tobacco, lack of sufficient physical activity and increasing lifespan will increase burden of various forms of cancer in near future (Report of the working group on disease burden for 12th five year plan, 2011). The major risk factors include the following:

\section{Substance abuse and addiction}

Substance abuse includes addiction to tobacco, alcohol and prohibited drugs. In India, usage of tobacco is rampant. Studies have shown that over $60 \%$ of men and $10 \%$ of women in the age group ranging between 15 to 49 years in addicted to some form of tobacco (Institute for Population Studies, 2007). It has also been observed that tobacco addiction is one of the highest risk factors for chronic pulmonary obstructive diseases (COPDs), cardiovascular diseases (CVDs) and several forms of cancer. $40 \%$ of all male cancers, in India, are caused due to addiction to some form of tobacco (Institute for Population Studies, 2007). Addiction to alcohol too is a major risk factor for commonly occurring NCDs. Reports have shown that around 10.6 million Indians are dependent on alcohol and thus fall under 
the risk category of cardiovascular diseases (CVDs), liver diseases and cancer to a greater extent (Kearney, 2005).

\section{Malnutrition}

Presence of both insufficient and excess quantities of nutrients is harmful for the body. Malnutrition covers both these imbalances and is turning out to be a major risk factor for NCDs. Thus, populations from all strata of life, irrespective of the financial and economic status, are falling prey to diabetes, cancer and other commonly occurring NCDs (World Health Organization). Overnutrition, along with decreased physical activity levels, are becoming a growing concern for the ever-expanding urban population of this country, which is poised to continue expanding at least over the next few decades (Stratton et. al., 2003; United Nations, 2012). Most of the processed foods available in the market these days require minimum processing before intake. In the effort to incorporate these properties in them, they are often enriched with compounds such as refined starches, saturated fatty acids, $\omega-6$ rich oils and high quantities of salts and sugars. Intake of all of them increases chances of various NCDs, such as cancers, diabetes, cardiovascular diseases, asthma (Singh et. al., 2007; Simopoulos, 1999; Simopoulos, 2008). Maternal overnutrition has been reported to increase the risk of developing obesity in the offspring (Toda et. al., 2012; Potdar et. al., 2014).

Undernutrition, especially maternal undernutrition, has also been found to predispose newborns towards developing diabetes, obesity and other forms of NCDs (Black et. al., 2008; Gluckman et. al., 2007; Robker et. al., 2009). Interestingly, some recent studies have also found link between paternal nutritional status and health of the offspring (Yajnik et. al., 2008). A recent report has revealed that child and maternal undernutrition are the predominant risk factors for NCDs in the EAG group of eight socioeconomically most backward states of India. In addition, unsafe lifestyle habits related to sanitation, handwashing and drinking water also predispose populations of these eight states to these diseases (Indian Council of Medical Research, 2017). On the other hand, the predominant risk factors in case of the socioeconomically better states include higher dietary risks due to excess intake of high calorie processed foods, physical inactivity, high BMI and high cholesterol levels (Indian Council of Medical Research, 2017).

Intervention strategies, such as providing protective diets rich in nuts, vegetables and fruits have been found to be beneficial against various forms of NCDs (Radford et. al., 2014). Patients suffering from myocardial infarction have also shown remarkable benefits from intake of diets rich in vegetables and fruits (World Health Organization, 2005; Fung et. al., 2008; Knoops et. al., 2004; He et. al., 2007).

\section{Physical inactivity}

Urbanisation has resulted in deep impact on the lifestyle of the Indian population. Availability of comfortable modes of transport and various gadgets for performing daily activities has decreased the amount of physical activity performed by the urban population in comparison to the rural population. This, coupled with availability of high calorie processed food material, has pushed the urban population towards obesity, high blood pressure, high cholesterol and diabetes (United Nations, 2012). It has been estimated that the urban Indian population will grow to a significant extent over the next 35 years (Stratton et. al., 2003).

\section{NATIONAL POLICIES TOWARDS ADDRESSING THIS ISSUE}

Government of India has already aligned all the national policies in line with the sustainable development goals and targets. The task of coordinating this alignment and ensuring adequate progress has been assigned to NITI Ayog (Heidemann et. al., 2008). In addition, Ministry of Statistics Planning and Implementation (MOSPI) has evolved national indicators for monitoring progress of the SDGs in March, 2017. These indicators have been developed in accordance with the global indicators (Heidemann et. al., 2008). The National Health Policy has also been reoriented alongwith the SDGs. The revised policy of 2017 clearly mentions its alignment with these goals, especially SDG-3. The policy has been developed with the aim of combating communicable and non-communicable diseases, universal health coverage and creating an appropriate health workforce (Heidemann et. al., 2008). In addition, the government has also passed several legislations keeping in view these SDGs. These include Mental Health Care Act (2017), Rights of Persons with Disabilities Act (2017), Human Immunodeficiency Virus and Acquired Immune Deficiency Syndrome Prevention and Control Bill (2017) and Maternity Benefits Amendment Act (2017) (Heidemann et. al., 2008)

\section{ONGOING PROGRAMS FOR GENERATING AWARENESS}

Keeping in view the growing threat of NCDs, several initiatives have been started by various organizations and employers with the aim of encouraging their workforce to develop and maintain healthy lifestyle. These policies and prevention programs are aimed towards smoking-free workspaces, alcohol-free workspaces, encouragement for regular exercises, periodic check up and monitoring of physical and mental health of employees (Economics of NonCommunicable Diseases in India, 2014). In addition, several intervention policies have been developed by the central government, various state governments as well as several NGOs. They have shown mixed progress. Some examples of such initiatives include National Programme for Prevention and Control of Cancer, Diabetes, Cardiovascular Diseases and Stroke (NPCDCS), Dietary salt reduction programme, Health systems strengthening project, HPV vaccination, Tobacco taxation, Tobacco regulation, Mobilizing Youth for Tobacco-Related Initiatives (MYTRI), Kidney Help Trust of Chennai, Indian Diabetes Prevention Programme (IDPP), Stepped Care Intervention for Depressive and Anxiety Disorders (MANAS) in Goa, WHO best buys (combination drug therapy for CVD), Bangalore Baptist Hospital (BBH) (community-level intervention for CVD prevention and management) (Economics of Non-Communicable Diseases in India, 2014). In addition, Mumbai Maternal Nutrition Project (MMNP), a nutrient supplementation project was undertaken with the aim of providing a nutrient-rich healthy snack to 
pregnant women. Significantly, this intervention was found to decrease gestational diabetes in pregnant women to a great extent (Sustainable Development Goals, 2017).

\section{CONCLUSION AND FUTURE DIRECTIONS}

The rapid increase in occurrence of NCDs among the Indian population is an alarming trend. Projected to become global epidemic capital of diabetes, this country and its people need to start addressing this issue on urgent basis. The matter is worsened by the fact that various undesirable lifestyle habits are predisposing the people towards various NCDs, including cancer, cardiovascular diseases and diabetes. Since majority of these risk factors are controllable at individual level, mass awareness generation is the need of the hour. Increased intake of fresh fruits and vegetables, heightened physical activity, staying away from various types of addictions are some of the avenues that hold promise. Mere policy formation and efforts only at the levels of the governments and NGOs will not be sufficient. Active participation by people from all walks of life and their full cooperation with the ongoing national/state level campaigns is the only ray of hope for a country which is already overburdened with incidence of a group of diseases which could have been prevented to a great extent at the beginning.

\section{REFERENCES}

[1] Achieving the Sustainable Development Goals in India: A Study of Financial Requirements and Gaps. Report by: Technology and Action for Rural Advancement, 2015.

[2] Black, R. E., Allen, L. H., Bhutta, Z. A., Caulfield, L. E., de Onis, M., Ezzati, M., Mathers, C., Rivera, J. Maternal and child undernutrition: Global and regional exposures and health consequences. Lancet, 2008, 371, 243-260.

[3] Economics of Non-Communicable Diseases in India: Executive Summary (World Economic Forum, 2014).

[4] Ezzati, M. and Riboli, E. Behavioral and Dietary Risk Factors for Noncommunicable Diseases. New England Journal of Medicine, 2013, 369, 95i4-964

[5] Fung, T. T., Chiuve, S. E., McCullough, M. L., Rexrode, K. M., Logroscino, G., Hu, F. B. Adherence to DASH- style diet and risk of coronary heart disease and stroke in women. Archives of Internal Medicine, 2008, 168, 713-720.

[6] Gluckman, P.D., Seng, C.Y., Fukuoka, H., Beedle, A.S., Hanson, M.A. Low birthweight and subsequent obesity in Japan. Lancet, 2007, 369, 1081-1082.

[7] He, F. J., Nowson, C. A., Lucas, M., MacGregor, G. A. Increased consumption of fruit and vegetables is related to a reduced risk of coronary heart disease: meta-analysis of cohort studies. Journal of Human Hypertension, 2007, 21, 717-728.

[8] Heidemann, C., Schulze, M. B., Franco, O. H, et al. Dietary patterns and risk of mortality from cardiovascular disease, cancer, and all causes in a prospective cohort of women. Circulation, 2008, 118, 230-237.

[9] IAEG-SDGs. Report of the Inter-Agency and Expert Group on the Sustainable Development Goal Indicators. New York, NY: Economic and Social Council, 2016. http://unstats.un.org/unsd/statcom/47th-session/documents/20162-SDGs-Rev1-E.pdf.

[10] Indian Council of Medical Research, Public Health Foundation of India, and Institute for Health Metrics and Evaluation. India: Health of the Nation's States - The India State-level Disease Burden Initiative. New Delhi, India: ICMR, PHFI, and IHME, 2017

[11] Institute for Health Metrics and Evaluation (IHME). Globa burden of disease study 2010: India global burden of disease study 2010 (GBD 2010) results 1990-2010. Seattle: IHME. 2013.
[12] Institute for Population Studies (IIPS). National Family Health Survey (NFHS-3), 2005-06. Mumbai: IIPS, 2007.

[13] Kearney, P.M., et al. "Global burden of hypertension: Analysis of worldwide data". The Lancet, 2005, 365 (9455), 217-223.

[14] Knoops, K. T. B., de Groot, L. C., Kromhout, D., et al Mediterranean diet, lifestyle factors and 10-year mortality in elderly European men and women. The HALE project. The Journal of the American Medical Association; 2004, 292, 1433 1439.

[15] Potdar, R. D., Sahariah, S. A., Gandhi, M., Kehoe, S. H., Brown, N., Sane, H., Dayama, M., Jha, S., Lawande, A., Coakley, P. J., et al. Improving women's diet quality preconceptionally and during gestation: Effects on birth weight and prevalence of low birth weight-A randomized controlled efficacy trial in India (Mumbai Maternal Nutrition Project). American Journal of Clinical Nutrition, 2014, 100, 1257-1268.

[16] Radford, E. J., Ito, M., Shi, H., Corish, J. A., Yamazawa, K., Isganaitis, E., Seisenberger, S., Hore, T. A., Reik, W., Erkek, S. et al. In utero effects. In utero undernourishment perturbs the adult sperm methylome and intergenerational metabolism. Science (New York, NY), 2014, 345, 1255903.

[17] Report of the working group on disease burden for 12th five year plan.

Online]. http://planningcommission.gov.in/aboutus/committee/wrkgrp12/h ealth/WG_3_2non_communicable.pdf. 2011.

[18] Robker, R. L., Akison, L. K., Bennett, B. D., Thrupp, P. N. Chura, L. R., Russell, D. L., Lane, M., Norman, R. J., Obese women exhibit differences in ovarian metabolites, hormones, and gene expression compared with moderate-weight women. Journal of Clinical Endocrinology and Metabolism, 2009, 94, 1533-1540

[19] Simopoulos, A. Essential fatty acids in health and chronic diseases. American Journal of Clinical Nutrition, 1999 70(Supp 3): $560-69 \mathrm{~s}$

[20] Simopoulos, A. P. The importance of the $\omega-6 / \omega-3$ fatty acid ratio in cardiovascular diseases and other chronic diseases. Experimental Biology and Medicine, 2008, 233, 674-88.

[21] Singh, R. B., Pella, D., Mechirova, V., et al. Prevalence of obesity, physical inactivity and undernutrition, a triple burden of diseases during transition in a developing economy. The Five City Study Group. Acta Cardiologica; 2007, 62, 119-127.

[22] Stratton, R. J., Green, C. J. and Elia, M. Scientific criteria for defining malnutrition Disease-Related Malnutrition. An Evidence Based Approach to Treatment CABI Publishing Wallingford: 2003

[23] Sustainable Development Goals: Agenda 2030 A Civil Society Report, Coordinated by Wada Na Todo Abhiyan, 2017.

[24] Taylor, D.W. The burden of non-communicable diseases in India. Hamilton, ON: Cameron Institute, 2010.

[25] Terzic, A. and Waldman, S., Chronic diseases: the emerging pandemic. Clinical and translational science, 2011, 4(3), 225226.

[26] The Inclusive Growth and Development Report, 2017. World Economic Forum

[27] Toda, E., Toru, T., Singh, R. B., et al. Effects of Paleolithic-style diet with emphasis on $\omega-6 /-3$ fatty acids ratio on coronary artery disease: the tissue is the issue. American Medical Journal, 2012.

[28] UN. Transforming our world: the 2030 Agenda for Sustainable Development. New York: United Nations, 2015. https:// sustainabledevelopment.un.org/post2015/transformingourworld

[29] United Nations (UN). World urbanization prospects: The 2011 revision. New York. 2012

[30] United Nations Millennium Project. Who they are. Retrieved from http://www.unmillenniumproject.org/goals/on November 11, 2015. Google Scholar

[31] World Health Organization. Preventing Chronic Disease: A Vita Investment World Health Organization, Geneva, 2005.

[32] World Health Organization (WHO). Prevention and control of noncommunicable diseases: implementation of the global strategy. Geneva: WHO. 2008 
[33] World Health Organisation. Global Health Risks: Mortality and Burden of Disease Attributable to Selected Major Risks; World Health Organisation: Geneva, Switzerland, 2009.

[34] World health organization. NCD country profiles. [Online]. http://www.who.int/nmh/countries/ind_en.pdf?ua=1. 2011.
[35] Yajnik, C. S., Deshpande, S. S., Jackson, A. A., Refsum, H., Rao, S., Fisher, D. J., Bhat, D. S., Naik, S. S., Coyaji, K. J., Joglekar, C. V., et al. Vitamin B12 and folate concentrations during pregnancy and insulin resistance in the offspring: The Pune Maternal Nutrition Study. Diabetologia; 2008, 51, 29-38. 